


\title{
Gerfanmmelte $\mathfrak{B} \mathfrak{e r f e}$
}

von

\section{Fring Emil von Edjonaid)=Earolath}

\author{
3roite 2uflage
}

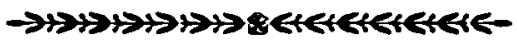

\author{
4. Band

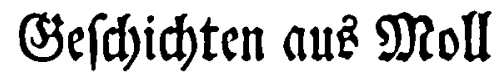

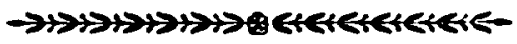

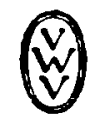

Bereinigung wiflenfdaftlider Berleger

Zaltber te Brugtre \& So.

cormals a. 9 gofdenime Berlagthancluna . 9. Gottentag, Berlegs

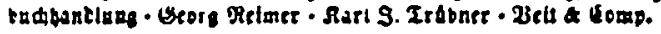

Berlin und \&eipjis

1922 


\section{Gefididften aus $\mathfrak{R o l l}$}

von

\section{Pring (mil bon Shónaid)=〔arolath}

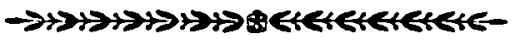

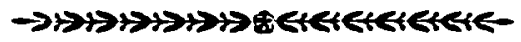

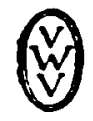

Bereinigung wiffenidaftlidher Berleger

Traltber be Gruyter \& 6 o.

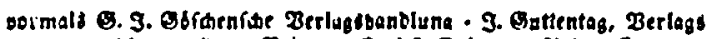

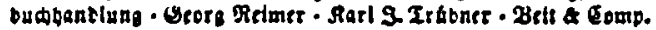

\section{Berlin und Seipjig}

19.22 


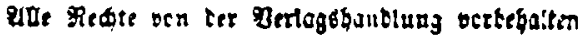


Amal la storia d'infelici amuri. La triste melodia, gli indi di planto.

E la farfalla, che rold sui fiori

D'un camposanto . . 
